\title{
O IMPACTO DA CRISE NO SERVIÇO SOCIAL
}

F. DIAS, E. DUQUE
Universidade Católica Portuguesa
eduardoduque@braga.ucp.pt
Submetido $05 / 10 / 2018$ - Aceito $29 / 12 / 2018$
DOI: $10.15628 /$ holos. 2018.7824

\section{RESUMO}

O presente estudo possui como objetivo central analisar o desemprego no seio do Serviço Social visando, principalmente, compreender as causas que o motivam numa era em que o trabalho do Assistente Social é fundamental devido à multiplicidade de problemas sociais existentes. A não inserção do Assistente Social no mercado de trabalho constitui uma problemática social preocupante. Desta forma, numa tentativa de compreender e explorar este problema social foi utilizada uma metodologia qualitativa com recurso a entrevistas realizadas a diplomados em Serviço Social pela Faculdade de Ciências Sociais da Universidade
Católica Portuguesa, Centro Regional de Braga. Concluiu-se que o modelo social envolvente constitui um dos maiores motivadores da crise que estamos a presenciar com consequências em múltiplas esferas da sociedade. O modelo social atual criou uma sociedade paradoxal preenchida por múltiplos profissionais formados, mas que não têm oportunidade de colocar em prática as suas habilitações por se encontrarem num mercado de trabalho saturado que não aproveita a mãode-obra qualificada que possui e que a cada momento a desrespeita quer pela falta de ofertas, quer pelas condições débeis que disponibiliza.

PALAVRAS-CHAVE: Serviço Social, Assistente Social, Modelo Social, Crise, Desemprego.

\section{THE IMPACT OF THE CRISIS ON SOCIAL WORK}

\begin{abstract}
The aim of this study is to analyze the unemployment in the Social Services, trying to understand the causes that motivate it. The non-insertion of the social worker in the labor market is a worrying social problem. Therefore, in an attempt to understand and explore this social problem we used a qualitative methodology doing some interviews to graduates in social service by the Faculty of Social Sciences of the Catholic University, Regional Centre of Braga. It was concluded that the surrounding
\end{abstract}

social model is one of the biggest causes of the crisis that we are witnessing with effects in multiple spheres of society. The current social model has created a paradoxical society filled by many trained professionals but who do not have the opportunity to put their skills into practice because they are in a saturated labor market that does not take advantage of the skilled workforce that they have and that each disrespect either by the lack of offers or by the weak conditions that it offers.

KEYWORDS: Social Work, Social Worker, Social Model, Crisis, Unemployment. 


\section{INTRODUÇÃO}

As últimas décadas têm vindo a ser marcadas por múltiplas transformações em diversos domínios da sociedade, nomeadamente na esfera laboral. O mundo do trabalho tem vindo a ser marcado pela incerteza, pela instabilidade e pela debilidade devido às diversas barreiras presentes no que se refere à inserção de profissionais no mercado de trabalho, incluindo na sua área de formação.

Os profissionais do Serviço Social não são exceção a esta realidade, sendo o desemprego e a precariedade laboral, realidades bem presentes e vincadas nesta área. Além de muitos profissionais não estarem a trabalhar na sua área de formação, aqueles que se encontram a trabalhar na área experimentam situações e contextos de precariedade, não estando a realizar em pleno o exercício da sua profissão, o que os leva a questionar a sua posição no mercado de trabalho, causando um sentimento de mal-estar e de desacreditar a nível profissional.

O emprego e o desemprego são duas realidades que sempre coexistiram. Contudo, nos últimos tempos, o desemprego assumiu preponderância no contexto social adotando uma nova faceta pelo facto de atingir todas as classes de trabalhadores, com maior ou menor formação.

Tal como Duque e Calheiros (2011: 49) referem, "os recursos humanos são cada vez mais excedentários. As dinâmicas de trabalho, sobretudo em Portugal, expressam claramente que a vida ativa encurtou, dado que as dificuldades de entrada no mercado de trabalho são imensas e as saídas cada vez mais precoces. Verifica-se também que o tempo de espera por um posto de trabalho é menor numa pessoa com elevados níveis de qualificação que num trabalhador indiferenciado". Contudo, é importante salientar que esta situação é alimentada também pela atual crise económica visto que a falta de meios financeiros que impossibilita a remuneração dos profissionais é altamente potenciadora da falta de emprego, levando ao desemprego.

O desemprego é uma realidade global, atingindo todas as categorias de profissionais. Contudo, esta realidade é ainda mais preocupante quando refletimos acerca dos profissionais diplomados devido ao tempo e ao esforço que dispensaram na sua formação sem adquirir o retorno positivo que tanto ambicionavam - emprego e valorização profissional na sua área de formação. Os licenciados em Serviço Social experimentam atualmente esta realidade, constituindo esta um grave problema social.

A missão do Serviço Social é zelar pelo bem-estar dos cidadãos, tentando solucionar os seus problemas sociais. Desta forma, este estudo foi desenvolvido para tentar compreender uma contradição existente que se prende com o facto de o desemprego ser uma realidade atual e vincada no seio do Serviço Social numa época em que o seu papel e intervenção são fundamentais.

O desemprego no Serviço Social em Portugal é motivado pela crise económica, pela falta de meios para remunerar os Assistentes Sociais e também devido à saturação do mercado de trabalho que se sente incapaz de acolher o elevado número de licenciados na área. Existe, portanto, um desequilíbrio entre o número de licenciados na área e o número de postos de trabalho disponíveis pois apesar de haver uma forte necessidade de intervenção destes 
profissionais dada a dimensão dos problemas sociais, não existe oferta de emprego suficiente na área. Contudo é importante salientar que esta realidade é principalmente motivada pelo facto de certas funções inerentes ao Serviço Social estarem a ser desempenhadas por profissionais externos à área bem como pela falta de reconhecimento da importância e do significado do Serviço Social sendo este um dos principais desafios que se impõe nos dias de hoje a esta profissão.

\section{ENQUADRAMENTO TEÓRICO}

\subsection{Breve abordagem à História do Serviço Social}

O Serviço Social possui já um século de existência enquanto campo e disciplina autónoma. Durante este período, o Serviço Social desenvolveu-se e procurou construir um percurso marcado pela reflexão, pela tentativa de intervenção, por novas ideologias e pela constante procura de políticas centradas na luta contra a injustiça social (Mouro e Simões, 2001).

Ao longo da sua história, o Serviço Social atravessou diversas fases que, por diversas vezes, se sobrepunham em função dos contextos e experiências de vários países. Desta forma, e resumidamente, seria importante relembrar algumas destas fases que marcaram a sua história.

Numa fase inicial, podemos destacar a Fase de Emergência Social (1890-1898), a Fase da Institucionalização (1897-1937), a Fase da Legitimação (1917-1930) e a Fase da Qualificação (19301960). Além destas fases, é igualmente importante destacar a Fase do Sincretismo (1960-1965), a Fase de Reidentificação (1965-1970) e, por último, a Fase da Afirmação (a partir dos anos 70).

Apesar de todas as fases aqui mencionadas possuírem relevância própria, neste trabalho, iremos apenas focar algumas dessas fases pelo facto de mais se coadunarem com a temática abordada no mesmo.

Inicialmente, no final do século XIX, o Serviço Social constituía um mecanismo de aperfeiçoamento da capacidade de "bem-fazer", sendo dominado por um sistema capitalista e marcado por um papel de legitimação das desigualdades sociais que o próprio sistema originava. O ponto central da institucionalização do Serviço Social foi a proposta da criação da Escola de Filantropia Aplicada por Mary Richmond, no final do século XIX (Mouro e Simões, 2001). Após este período, o Serviço Social começa a ser estruturado como uma profissão profundamente ligada às respostas conjunturais (nomeadamente depois das dificuldades sentidas após a Primeira Guerra Mundial) e à arbitragem de conflitos que Ihe confere algum reconhecimento (Mouro e Simões, 2001).

Desde os seus inícios que a profissão esteve ligada à dimensão psicossocial uma vez que atribuía uma grande importância aos problemas sociais individuais.

A Fase da Legitimação é influenciada pela crítica de que a atuação profissional era muito marcada pela visão caritativa assistencial. Verifica-se, desta forma, um predomínio da escola funcional marcada pelos objetivos de ação empírica, valorização do investimento na formação e 
valorização da intervenção (Mouro e Simões, 2001). Já na Fase da Qualificação, a sistematização dos conhecimentos empíricos ganha importância sendo que nesta fase verifica-se um novo estilo de atuação marcado por um discurso mais isento, valorizando-se progressivamente o conceito de cidadania (Mouro e Simões, 2001).

O período em que o Serviço Social esteve mais ligado ao Estado Providência (anos 60/70) ampliou a crítica dentro da própria profissão devido à dimensão moralizadora e normativa da atuação profissional questionando-se, particularmente, a imagem do assistencialismo que estigmatizava o seu solo histórico, obedecendo a uma racionalização operativa que permanece na atividade (Mouro e Simões, 2001).

De acordo com Carvalho (2011), o Estado Providência e o Serviço Social possuem uma história em comum, pois, o processo de desenvolvimento do Estado Social corresponde ao desenvolvimento do Serviço Social. Na Europa, desde a segunda Guerra Mundial até aos anos 70, assistiu-se a um grande desenvolvimento e promoção do Estado Providência e do Serviço Social. 0 Serviço Social clássico, por sua vez, insere-se neste projeto onde há instituições e profissionais qualificados que visavam reduzir as diferenças entre grupos populacionais de uma dinâmica de progresso social que atravessava a sociedade. Este tinha um papel de controlador e de normalizador social, procurando reabilitar os indivíduos com vista à sua integração na sociedade. Neste período é colocado em causa um modelo de integração, de construir a sociedade com os seus semelhantes onde houvesse estabilidade entre todos (Carvalho, 2011).

Assiste-se, entretanto, a uma crise do Estado Providência e verifica-se a saída do capitalismo industrial que, por sua vez, põe em causa o modelo de integração baseado na inclusão de estruturas de trabalho estáveis. Carvalho (2011) sustenta ainda que esta situação se verificava devido à precarização dos laços laborais e do desemprego de massas. Verificou-se também uma crise do modelo de integração e assistiu-se à mobilidade generalizada das estruturas e indivíduos, dificultando a integração de pessoas em estruturas estáveis. Tudo isto traz implicações no seio do Serviço Social, pois, surgem novos públicos distintos do Serviço Social clássico (desempregados, jovens à procura do primeiro emprego e novos pobres) e, por sua vez, surgem novos problemas sociais.

Além disso, verificou-se uma recomposição das intervenções sociais através da inserção e da territorialização. A inserção traduz-se por uma transição, uma forma original de acompanhamento de novos públicos com dificuldades de integração que deveria de desembocar no regresso ao trabalho e na resolução de problemas quotidianos (Carvalho, 2011). No que diz respeito à territorialização, as intervenções sociais possuem um caráter local a nível de gestão e de planeamento dos programas sociais. Estas intervenções não são tuteladas apenas por um organismo e implicam a participação de todos os atores da comunidade. As coletividades locais ficam responsabilizadas por programas sociais. As intervenções sociais herdam estas dificuldades e traduzem-nas em novas práticas (noção de contrato, de projeto e de ativação) (Carvalho, 2011). A lógica da contrapartida está ajustada a uma situação particular em oposição à lógica de atendimento por categorias abstratas de beneficiários/ cidadãos com direitos. Substitui-se, assim, a lógica de assistência pela lógica de inserção onde os direitos se individualizam e se contratualizam e onde o Assistente Social se torna um gestor minucioso desta nova dinâmica de 
direitos e deveres. As intervenções tornam-se mais complexas e é necessária mais imaginação e iniciativa para acompanhar uma pessoa na sua trajetória. Contudo, estas orientações só se tornam possíveis baseadas em apoios coletivos, pois, só assim, se consegue enfrentar a individualização dos problemas. É aqui que a presença do Estado se impõe como garantia das condições mínimas de independência social em nome da coesão social (Carvalho, 2011).

De acordo com Reamer (apud Mouro e Simões, 2001), as questões da ética profissional acompanham as metamorfoses que a profissão foi sofrendo ao longo dos tempos. Primeiramente, vigoram as preocupações paternalistas, morais e religiosas sendo de salientar que, em 1919, surgiu a primeira tentativa de impor um código de ética à profissão. Ao longo dos tempos, o trabalho social foi evoluindo e, nos anos 60 , os seus valores encontravam-se fortemente instalados, estando a intervenção centrada nos domínios mais valorizados na época como os direitos humanos e civis, a justiça social, a igualdade e o respeito pelos outros indivíduos da sociedade. Na década de 80 , a ética no trabalho social toma um novo rumo relacionado com as fronteiras da profissão. O Serviço Social preocupa-se com questões éticas e, naturalmente, consagra a confidencialidade e a privacidade. É importante referir que os problemas éticos do Serviço Social se devem às metamorfoses políticas e sociais que se verificaram ao longo dos tempos. Segundo Sarah Banks (apud Mouro e Simões, 2001) há orientações com impacto nos valores da profissão como a especialização e fragmentação do trabalho, desenvolvimento do trabalho multidisciplinar e crescimento dos procedimentos do governo institucional. $\mathrm{O}$ assistente social assume um papel de monitorização, vigilância e recolha de provas, o que resulta na burocratização do trabalho social.

Neste contexto, este deixa de ser um profissional reflexivo a utilizar o discernimento profissional para começar a assumir antes um papel de técnico a cumprir regras. Verifica-se que a grande necessidade de pedidos institucionais onde se trabalha diminui a possibilidade de um trabalho individual e coletivo focado no desenvolvimento. Tal como Yolanda Guerra refere (1995, apud Mouro e Simões, 200), a tendência atual de individualização em detrimento do coletivo, do pragmatismo em detrimento da ideologia e da reflexão e do curto prazo em detrimento do processo de mudança são críticas para a profissão. É necessário incorporar as transformações sociais globais em desenvolvimento e refletir sobre o posicionamento do Serviço Social.

Na história do Serviço Social, a Fase do Sincretismo (1960/1965) assume uma importância particular. Neste período, a conduta profissional caracterizava-se por atribuir um caráter global e indiferenciado à atuação em terreno, o que permitiu fortalecer vínculos institucionais usados para consolidar o pensamento conservador no que se referia ao controlo social bem como na sua entrega ao estatuto polivalente de corpo intermédio na relação do poder com a sociedade civil. Tudo isto Ihe atribuía um cunho reformista devido à modificação da sua experiência prática fruto da evolução de diferentes contornos do sistema de gestão social a nível histórico e conjuntural (Mouro \& Simões, 2001). Esta tendência afirma-se quando o Serviço Social decide beneficiar a valorização de uma prática profissional baseada numa cultura de comportamento ideológico.

O processo descontinuado de qualificação do Serviço Social aguçou uma erosão e desfasamento no perfil da sua identidade profissional, contribuindo também para uma crescente dessincronização existente na sua vertente social de projeção profissional (Mouro \& Simões, 
2001). Verificava-se, por um lado, um avanço do Serviço Social no sentido de definir o seu espaço profissional de acordo com a articulação entre os interesses de um crescimento profissional marcado por uma valorização profissional e as necessidades históricas e sociais. Por outro lado, assistia-se a um desenvolvimento do Serviço Social baseado na dinâmica do processo político e na adaptação da sua cultura técnico-profissional às necessidades instrumentais da política social. Portanto, o padrão de reconhecimento profissional resulta da junção de duas formas operatórias de identificar os diferentes parâmetros em que se mediatiza a identidade profissional.

Inicialmente, falava-se de uma prática profissional do Serviço Social como resultado das condições de cariz histórico-sociais de emergência, mas a sua dinâmica de consolidação profissional passou a ter como base a prática da sua atuação (Netto, 1992 apud Mouro \& Simões, 2001). É importante salientar que, no que se refere à atuação profissional, a fragilização da identidade histórica do exercício profissional levou a uma descaracterização da sua ação pois na sua atividade, o Serviço Social confundia o acidental com o essencial, possuía uma atitude profissional imitativa e empenhava na resolução de conflitos secundários (Mouro \& Simões, 2001).

As alterações no seu comportamento profissional são fruto de um descondicionamento na necessidade de ter de lutar por uma afirmação no mercado de trabalho. A pragmatização política da ideia do Estado-Providência por parte do capitalismo levou o poder político a reorientar e a redirecionar as suas formas de intervenção na ação social. A redefinição do conceito de bem-estar social bem como o alargamento dos benefícios sociais como forma de o capitalismo desenvolver e fazer valer a sua política pautada pela igualdade e pela solidariedade fazem com que haja uma maior necessidade de investir nas políticas sociais. Desta forma, assistiu-se a um aumento das respostas funcionais e institucionais que moldam a redefinição da tomada de decisão do poder político na área social (Mouro \& Simões, 2001). Desta forma, o Serviço Social presencia o desenvolvimento no campo da atuação profissional (Mouro e Carvalho 1987: 52 apud Mouro \& Simões, 2001).

A reformulação ideológico-concetual da ideia de necessidade social e com o alargamento de novos espaços de atuação profissional, a ação prática do Serviço Social passa a estar focada não só no indivíduo enquanto problema, mas, principalmente, no sentido de privilegiar uma visão tecnológica da gestão do campo social. A fragilização da sua identidade histórica levou a um questionamento dos seus limites históricos. O seu caráter ideológico também foi alvo de uma certa controvérsia devido à sua vinculação ao Estado (Mouro \& Simões, 2001) que, por ser um grande empregador dos Assistentes Sociais, levou a uma desertificação na imagem profissional do Serviço Social. Esta situação desenvolveu-se e agravou-se progressivamente devido principalmente à crise da legitimação do Estado de bem-estar social e complicou-se devido à burocratização do funcionamento do sistema de segmentarização social.

Devido a esta situação, o Serviço Social reage com um esvaziamento no seu imaginário profissional, assumindo uma postura hermética. A setorização da atividade profissional do Serviço Social fez com que o mesmo perdesse o seu carisma socioprofissional (Mouro \& Simões, 2001).

Segundo alguns estudos sobre o estado atual da formação em Serviço Social em Portugal (Martins \& Tomé, 2008) realizado no âmbito do núcleo de estudos e de investigação do Mestrado 
em Serviço Social, verificou-se que o curso de Serviço Social foi incluído na área dos serviços sociais e, segundo o mesmo relatório, 4,5\% dos diplomados em estabelecimentos de ensino superior são da área dos serviços sociais. Esta área diplomou 12.719 alunos, número que corresponde a 2,2\% do total de licenciados nos períodos compreendidos entre 1996/1997 e 2005/2006. Neste mesmo período, licenciaram-se 5.869 alunos em Serviço Social e, no final de 2007, o centro de emprego possuía 812 assistentes sociais inscritos sendo que uma grande parte procurava o primeiro emprego. Apesar de o nosso país ainda estar longe de atingir as percentagens de licenciados no ensino superior dos países mais desenvolvidos da União Europeia, o mesmo possui já problemas de desemprego. Portugal não pode dispensar de recursos humanos especializados, mas, nos últimos anos, tem-se verificado, de acordo com dados do Instituto Nacional de Estatística, uma redução substancial do emprego na administração pública. No Serviço Social tem-se verificado, nos últimos anos, um desenvolvimento desta licenciatura em escolas privadas, públicas e um aumento do número de vagas, inscritos e licenciados. Além disso, tem-se verificado também uma perda progressiva do emprego na administração pública que não é contrariada pela criação de novos empregos noutros setores de atividade.

Seguindo estes estudos, e no que se refere ao mercado de trabalho dos assistentes sociais, podemos dizer que, de acordo com dados recolhidos entre 1996 e 1999, estes profissionais vinculados à administração pública trabalhavam essencialmente no Ministério da Justiça, no Ministério da Solidariedade e Segurança Social, no Ministério da Saúde e nas Câmaras Municipais. As áreas onde havia uma menor empregabilidade destes profissionais eram o Ministério do Ambiente, da Defesa e da Administração Interna.

De acordo com Carvalho (2010) esta é uma profissão essencialmente feminina sendo que, aproximadamente, 3.000 pessoas ligadas ao social são sócias da APSS (Associação de Profissionais do Serviço Social). A sua ação exerce-se na Administração Central (Ministérios e Instituições públicas) e Local (Câmaras Municipais e Juntas de freguesia), em Organizações Não Lucrativas e algumas Lucrativas bem como em empresas. Na Administração Central inserem-se em políticas setoriais nas áreas do Serviço Social (ação direta, luta contra a pobreza, crianças e jovens em situação de risco, apoio aos idosos, deficientes e toxicodependentes), principalmente na concretização de suportes económicos e sociais; na área da saúde e nos cuidados primários (cuidados continuados, pessoas dependentes, gabinetes do utente e atividades de prevenção), nos hospitais (apoio psicossocial aos doentes, à sua família e continuidade de cuidados ao domicílio) e ainda nos centros de tratamento de toxicodependência. Além disso, no mercado de trabalho dos assistentes sociais incluem-se atividades na área da justiça, nomeadamente, na reinserção social dos reclusos e estabelecimento de planos de reinserção social. Os assistentes sociais exercem também a sua atividade na área do emprego e da formação, acompanhamento de cursos de formação para uma população vulnerável. Na educação e na habitação, a sua atuação é menos expressiva, inserindo-se na área de ação social/ sociocultural e de saúde e/ou habitação das autarquias onde desenvolvem projetos comunitários e de promoção do bem-estar da população (Carvalho, 2010). Nas organizações não lucrativas podemos inserir as IPSS onde os assistentes sociais podem exercer a sua profissão em empresas na área dos serviços sociais de apoio aos funcionários e em seguradoras, embora haja um número pouco significativo (Carvalho, 2010). 
No nosso país não existe uma profissão liberal em Serviço Social, mas, ultimamente, tem surgido empresas associadas ao cuidado do idoso, lares e ajudas domiciliárias que recrutam assistentes sociais para exercer a atividade no setor público (Carvalho,2010).

De acordo com Chaves (2010), a política social constitui-se como um dos fatores contextuais de grande alcance para o Serviço Social tendo como pano de fundo as alterações bem como as tendências de mudança societal contemporânea. O Serviço Social enquanto profissão, cuja emergência precede à construção do Estado social, é indiciadora e encontra-se inscrita nos movimentos do Estado liberal para a forma do Estado moderno, configurando um específico modo de regulação e de dispositivos institucionais traduzidos em políticas sociais. O Serviço Social como profissão encontra-se inserido na estratégia de regulação social do Estado moderno e a relação existente entre Serviço Social, Estado e política social encontra-se dominada pela dependência, autonomia, necessidade e conveniência, de extensão e retração do Estado. $O$ desenvolvimento do Serviço Social como profissão e como disciplina insere-se no contexto do crescimento da intervenção do Estado bem como da sua solidificação enquanto Estado de bem-estar.

De acordo com a mesma autora (2010), devido à intensidade do processo de globalização, nos últimos anos vivemos num contexto de mudança e assiste-se à construção de novas formas e relações a nível dos processos de regulação social, das instituições e da ação dos agentes sociais e, ao mesmo tempo, altera-se a configuração da relação entre Estado, mercado e cidadãos. O Serviço Social enquanto formação da modernidade bem como da estratégia de regulação do Estado de bem-estar faz parte destes processos de mudança social designadamente através da ação dos profissionais nas instituições e organizações e ao nível da formação dos assistentes sociais. Nesse sentido torna-se necessário compreender quais são os impactos destas mudanças para o Serviço Social nomeadamente a nível das políticas sociais. As sociedades estão a experimentar um enorme processo de mudança social que está a acontecer de forma veloz e que afeta direta ou indiretamente o nosso dia-a-dia embora de forma distinta devido ao contexto em que cada um de nós se encontra inserido.

As diferentes mudanças em curso são vistas de maneira diferente. De acordo com Castel (1997) a crise da sociedade salarial designa-se por "Nova Questão Social" onde o desemprego estrutural e a desintegração social provocada pela perda dos laços sociais motivados pela vida profissional se tornam nos pontos fulcrais no que diz respeito à perda da coesão e identidade. As necessidades na nova economia global são acompanhadas pelo aumento do desemprego, da desigualdade e da pobreza. Como referem Duque e Calheiros "os fenómenos de 'exclusão social' sucedem-se à escala global, em territórios onde aparentemente não era suposto tal realidade acontecer" (2011: 48). E não deixa de ser curioso, chamam a atenção os autores do artigo, que "o conceito de 'exclusão social' surja no vocabulário político pela mão dos governos socialistas franceses nos anos 80 , os quais pretendiam com esta noção designar o conjunto de pessoas que viviam à margem da sociedade e sem proteção social. O seu uso generalizou-se e passou a designar também a solução do próprio problema. Por isso mesmo, o vocábulo 'exclusão social' passou a estar intimamente associado à 'coesão social'" (2011: 48). Neste contexto, o social surge cada vez mais associado às desigualdades, à pobreza e à exclusão social. 
Existem novas desigualdades diferentes das do passado, pois, as da atualidade são estruturais e multidimensionais. Há cada vez mais um fosso entre ricos e pobres bem como entre inclusão e exclusão devido a fatores simbólicos, culturais e sociais.

A diversidade étnica, cultural e religiosa que caracteriza cada vez mais as sociedades contemporâneas dificulta a inclusão social.

A nível demográfico, em resultado destas mudanças motivadas pela globalização, verificase um envelhecimento e prolongamento do tempo de vida da população possuindo um impacto significativo no campo social. A migração, bem como os processos de diáspora favorecem a diversidade e a diferença cultural das sociedades. Há cada vez mais uma tendência para viver sob um panorama de insegurança e de incerteza sendo esta insegurança produzida, de acordo com Becker pelo processo de desenvolvimento. As pessoas tornam-se cada vez mais individualizadas e o desenvolvimento económico e social moderno criou um viver em sociedade que é, cada vez mais, exigente e oferece menos laços e caminhos.

\subsection{Trabalho, Emprego e Desemprego}

Para a compreensão da temática do desemprego é importante, primeiramente, abordar alguns conceitos como o trabalho, o emprego e o desemprego tentando, simultaneamente, compreender a sua evolução ao longo dos tempos.

De uma forma geral, podemos referir que o trabalho corresponde a uma necessidade natural do ser humano uma vez que este é essencial quer à sua existência, quer à sua sobrevivência. Segundo Duque (2013: 81-82) "para a larga maioria das pessoas ter um trabalho representa a satisfação das necessidades básicas que permite a resolução dos problemas do diaa-dia, para outros, o trabalho é entendido num contexto de autorrealização pessoal, em que se valoriza mais a sua qualidade que os benefícios económicos que dele podem decorrer". Portanto, o trabalho constitui, por um lado, uma garantia de subsistência do ser humano que exerce a sua atividade profissional para auferir de um rendimento que utiliza para adquirir os bens essenciais à sua sobrevivência, mas, por outro, uma fonte de realização pessoal.

É comum ouvir expressões como "gosto do que faço", "trabalho por vontade", "se não trabalhar, a vida não tem sentido". Estas e muitas outras expressões não são mais do que formas que revelam o grau de identificação do indivíduo com o seu trabalho, permitindo depreender até que ponto ele é central para a identidade do sujeito (Duque, 2013: 82).

É lícito afirmar que o trabalho marcou sempre presença na vida do ser humano, tendo contribuído fortemente para o desenvolvimento da sociedade. Portanto, podemos referir que o trabalho contribuiu bastante para a aquisição de conhecimento a diversos níveis, para o sentimento de satisfação pessoal e profissional, bem como para o desenvolvimento económico do mundo em geral (Marx, 1985). Marx sustenta ainda que o trabalho constitui uma interação do Homem com o mundo natural sendo que os elementos deste último são conscientemente modificados para alcançar um determinado propósito. $O$ trabalho é a forma pela qual o homem se apropria da natureza para satisfazer as suas necessidades (Marx, 1985). 
De facto, concordamos com Duque (2013: 82) quando refere "independentemente da forma como cada um se situa perante o trabalho, o que aqui se supõe, é que ele constitui, de alguma forma, um fator fundamental na vida da pessoa. Portanto, a importância que ele ocupa (centralidade) é variável de pessoa para pessoa e inclusive pode ser diferente em cada etapa de vida do indivíduo.

Marques (2006) refere que a definição de trabalho implica considerar variáveis de caráter social, geográfico e etário e ainda tomar em consideração o comportamento da sociedade ao nível da economia, da cultura e do lazer visto que estas variáveis se encontram profundamente relacionadas com a sua situação profissional. O conceito de trabalho abrange quer variáveis quantificáveis como o rendimento auferido, quer variáveis qualificáveis como, por exemplo, a satisfação e a realização pessoal. O trabalho constitui, portanto, um bem que contribui para o bem-estar do indivíduo a todos os níveis. Ao longo dos tempos, o conceito de trabalho sofreu um processo de metamorfose visto que a cada período de tempo correspondiam diferentes aspetos culturais, sociais e políticos. Consoante os tempos, as necessidades e as prioridades desenvolviam-se e alteravam-se. Atualmente, o trabalho envolve a atividade executada em si sendo um esforço planeado e coletivo.

De acordo com certos padrões culturais e sociais, cada sociedade possui uma ideia própria e característica do que é o trabalho atribuindo-lhe um maior ou um menor valor. As mudanças na sociedade ditam as alterações no trabalho e, da mesma forma, a sociedade e os indivíduos também são diferentes na forma como interpretam e valorizam o trabalho. $O$ trabalho não se encontra única e exclusivamente ligado à vertente económica (Antunes, 2000).

Segundo Antunes (2000), as metamorfoses provocadas pela industrialização trouxeram algumas mudanças no contexto laboral do trabalhador fazendo com que o mesmo sentisse uma falta de identificação com o novo ambiente laboral que estava a presenciar. Com estas alterações surgem também algumas mudanças na Lei que são favoráveis pois visavam uma maior justiça laboral. Nesta ocasião, surgiu o direito do trabalhador criado para defender os trabalhadores a diversos níveis como, por exemplo, em casos de despedimentos sem justa causa, aquando da realização de horas de trabalho excessivas sem remuneração, perante más condições de higiene, para a elaboração de seguros contra acidentes, entre outros. Neste contexto de desenvolvimento da produção industrial e devido à produção em massa era urgente promover a eficiência e a eficácia laboral visando uma racionalização da mesma e do seu tempo de execução. Desta forma, surge a abordagem Taylorista do trabalho que consistia na tentativa de produzir o maior número de peças no menor tempo possível sendo que aqui a eficiência era colocada em primeiro lugar, desprezando-se as necessidades do trabalhador. Esta abordagem era, portanto, um fracasso e para a substituir surgiu a abordagem sociotécnica que promovia um trabalho mais humanizado bem como uma maior democratização da empresa, salientando e valorizando as necessidades e as qualidades dos trabalhadores.

Continuando com o mesmo autor, os conceitos de trabalho e de emprego são diversas vezes confundidos e assumidos como sendo a mesma realidade. Apesar de se encontrarem profundamente interligados, os conceitos de trabalho e de emprego são distintos. $O$ trabalho existe a partir do momento em que o ser humano diversifica e modifica o meio que o rodeia 
sendo que utiliza instrumentos que contribuem para a realização do seu trabalho. Abordando a conceito de emprego, podemos referir que este, por sua vez, é um conceito mais recente tendo surgido apenas aquando da Revolução Industrial e baseava-se numa relação de troca em que um indivíduo disponibilizava o seu trabalho e os seus serviços em troca de uma remuneração. De um modo geral, o emprego constitui um cargo ou uma ocupação de um indivíduo numa empresa ou num órgão público (Outhwaite \& Bottomore, 1996).

Ao longo dos tempos, os tipos e as formas de trabalho foram-se alterando visto que os seus padrões são fortemente influenciados pela época em que se vive. Há muitos anos, a escravatura dominou algumas sociedades a nível mundial. Nestes casos, o ser humano mais poderoso na sociedade assumia direitos de propriedade sobre outro ser humano mais vulnerável. Este indivíduo, o escravo, era tratado como um objeto, sendo obrigado a trabalhar gratuitamente, sem qualquer benefício. Com o passar dos tempos, os direitos do Homem foramse afirmando e o trabalho adequado e remunerado começou a marcar presença na sociedade. A evolução da sociedade possibilitou a afirmação de muitos direitos a nível profissional, permitindo ao cidadão trabalhar de forma digna e ser recompensado justamente pelo seu trabalho.

Vivemos cada vez mais num mercado onde a competitividade está presente e, perante este cenário, as empresas sentem necessidade de se adaptarem a esta nova realidade.

A globalização dos mercados e as suas consequências na conduta económica, política e social tem vindo a assumir uma importância cada vez maior criando um cenário onde a competitividade surge como um fenómeno imperativo. A questão da competitividade é hoje um termo bastante comum e abordado no seio das nações e das empresas devido às múltiplas metamorfoses verificadas a título mundial. Tal como sustenta Mariotto (1991), este termo é bastante importante uma vez que hoje compreendemos a importância de as empresas inovarem e se diversificarem para evitar a concorrência de outras empresas rivais. Desta forma, podemos referir que a competitividade se prende com a capacidade de uma determinada empresa ser bem-sucedida em mercados onde se verifica concorrência de potenciais rivais. Esta prende-se com a capacidade de qualquer organização cumprir a sua missão com mais êxito do que outras organizações e baseia-se na aptidão para conseguir satisfazer as necessidades e expetativas dos clientes e cidadãos, obtendo uma rentabilidade igual ou superior aos seus rivais de mercado.

Como referia Darwin (op. cit. Mariotto, 1991: 37). na sua obra Origem das Espécies "alguns cometem o erro inveterado de considerar as condições físicas de uma região como as mais importantes para os seus habitantes; ao passo que não pode ser questionado, penso eu, que a natureza dos outros habitantes, com as quais cada um tem de competir é geralmente um elemento bem mais importante de sucesso".

É de conhecimento geral que a competitividade é um conceito cada vez mais em voga nos dias que correm. Perante o crescente aumento de oferta de novos e variados produtos, as empresas sentem necessidade de inovar, de competir, de se tornarem melhores como forma de defenderem o seu próprio negócio. Desta forma, estas empresas recorrem a novos e diversificados métodos visando enaltecer aquilo que têm para oferecer e de forma a tornarem-se 
melhores do que os seus potenciais rivais.

Contudo, é importante salientar que a competitividade deve surgir da vontade de se autodesenvolver e se tornar melhor do que já é, e não pela ideia de ocupar o espaço de outra pessoa ou se tornar melhor do que o outro (José Roberto Marques in Coaching e Psicologia acedido em 02/01/2016).

Muitas pessoas encaram a competitividade como algo pejorativo, pois assumem que esta se refere a uma característica de pessoas que se querem enaltecer nem que para isso tenham de prejudicar os outros. Nesse sentido acredita-se que quanto menos competitiva for a empresa, mais beneficiada ela será devido a um ambiente de trabalho mais sadio. Tal como sustenta José Roberto Marques, especialista em Coaching e psicologia, os funcionários competitivos têm uma tendência para colocar o bem-estar organizacional abaixo de seu sucesso individual, fazendo com que o ambiente da empresa seja preenchido com uma multiplicidade de sentimentos negativos, ou seja, com um ambiente bastante mais desleal.

É lícito afirmar que a competitividade sadia é bastante vantajosa para o desenvolvimento de uma empresa uma vez que torna o funcionário mais dedicado ao trabalho. Contudo, é importante salientar que a competitividade possui muitas vezes uma conotação negativa visto que muitos funcionários procuram destaque e notoriedade e, nesse sentido, muitas vezes não olham a meios para atingir fins e beneficiar do reconhecimento que tanto almejam e, por isso, cria-se um ambiente de intriga e de competição doentio prejudicando quer os funcionários, quer a própria funcionalidade da empresa. Perante este sentimento de competição, o trabalho em equipa sai prejudicado pois o funcionário que deseja destaque procura fazer as tarefas sozinho para conseguir o reconhecimento individual.

A competitividade irracional retira a sincronia enérgica dos colaboradores, tornando-os pessoas individualistas e que não sabem aproveitar a oportunidade de trabalhar em equipa que tantas vantagens traz à empresa pela partilha de ideias.

Este fenómeno é cada vez mais visível na nossa sociedade, visto que vivemos num mercado competitivo onde os empregos são cada vez mais escassos e já só quase existe lugar para os melhores. A vontade quase voraz de conseguir um emprego nos dias de hoje faz com que as pessoas adotem este tipo de atitudes por temerem o desemprego.

Perante esta nova conjuntura, torna-se importante abordar a temática que, infelizmente, domina a atualidade - a situação da falta de emprego/ desemprego. De acordo com Marques (2009), a falta de emprego bem como esta situação que hoje presenciamos a nível laboral marcada pela precariedade e incerteza, possui consequências calamitosas a nível económico, social e político que se encontram intimamente relacionadas com a crise da produção que conduz ao desemprego. Ainda lembrando o mesmo autor, o estudo do fenómeno do desemprego é relativamente recente dado que apenas nos anos 80 se tornou um tema socialmente visível e, portanto, com necessidade de investigação visto que desde essa época se tem vindo a assistir a um aumento significativo e progressivo do desemprego. O desemprego é um produto histórico de uma sociedade baseada no mercado, o capitalismo, onde tudo foi transformado numa mercadoria sendo a força do trabalho um alvo central desta mudança. De 
acordo com Tumolo (2004), as vivências do ser humano são um produto histórico que se encontram fundadas na lógica do capital no seu movimento contraditório, não estando apenas centradas no desemprego enquanto fenómeno social isolado. Tumolo (2004) refere que o desemprego é um dos maiores problemas da contemporaneidade sendo, por isso, foco de uma profunda análise.

De acordo com Pochmann (2001 apud Tumolo, 2004), em 1999 um em cada três trabalhadores no mundo estava numa situação de desemprego ou de subemprego. A falta de emprego é, definitivamente, um dos grandes problemas do século não só pelos seus efeitos a nível económico, mas também pelas suas consequências a nível social. A falta de trabalho atinge particularmente o trabalhador e a sua família. A pessoa que se encontra desempregada sente-se inútil, com baixa autoestima visto que sente que não contribui para o desenvolvimento da sociedade nem mesmo para as despesas da casa onde vive. As vivências e experiências de desemprego são múltiplas e experimentadas de forma particular de indivíduo para indivíduo. Inerentes a esta situação de ausência de emprego, existe uma diversidade de consequências objetivas e subjetivas que afetam o indivíduo desempregado e que diferem em função de alguns fatores.

Relativamente às consequências objetivas, ou seja, às consequências mais diretas do desemprego destacamos a perda do rendimento salarial. Sem emprego, os indivíduos deixam de receber um salário e, dependendo dos casos, começam a receber um subsídio de desemprego que é sempre inferior ao salário anteriormente obtido pelo exercício da atividade profissional. Esta situação conduz a uma certa vulnerabilidade económica pois as despesas do indivíduo continuam a ser as mesmas tendo de ser pagas com um rendimento inferior. Estas dificuldades aumentam quando o indivíduo não consegue encontrar trabalho durante o tempo que tem direito a auferir do subsídio de desemprego. Um tempo depois de auferir da totalidade do subsídio de desemprego, quando reúne as condições para receber o mesmo, este é diminuído até ser totalmente retirado. Há pessoas que pelo facto de não terem conseguido encontrar trabalho nesse prazo se viram confrontadas com a ausência total de rendimento. Esta situação é bastante complicada pois conduz a uma inevitável fragilidade económica podendo, em alguns casos, falar-se de risco de pobreza.

Nestes casos de vulnerabilidade económica, o sujeito desempregado sente-se incapaz e dependente pois, por necessidade de sobreviver, este vê-se obrigado a recorrer a ajuda de familiares. Tudo isto faz com que este se sinta um encargo relativamente às pessoas que o ajudam, contribuindo para aumentar o seu sentimento de culpa, de vulnerabilidade e de fragilidade económica. Tal como Tumolo (2004) refere muitas vezes verifica-se tensão no seio familiar. Algumas vezes, o desempregado não pode contar com o apoio da sua família ficando desamparado financeiramente. Os cônjuges geralmente são descritos como indivíduos que fornecem apoio afetivo e material pois estimulam a procura de emprego e assumem as despesas da família. Contudo, verifica-se uma perda da qualidade da relação entre o casal pelas preocupações geradas pelo desemprego uma vez que há uma consciência de responsabilidade em prover os bens necessários para os filhos e simultaneamente a preocupação em não conseguir cumpri-la. 
O mesmo autor sustenta ainda que a quebra do padrão de consumo é um fator central e consequente da situação de desemprego. Os desempregados não conseguem renovar os seus bens, vendem bens para conseguir dinheiro e, por vezes, contraem dívidas. Nesta fase de privação de emprego, os desempregados sentem uma perda do poder de decisão sobre a conduta das suas vidas pois o desemprego gera uma dependência de outras pessoas que são os provedores das suas necessidades básicas.

Além disso, verifica-se um certo distanciamento social e diminuição de encontros sociais devido à tentativa de reduzir despesas.

O trabalho possui junto da maioria das pessoas um papel central. Todas as pessoas atribuem bastante valor ao seu emprego uma vez que é este que lhes permite ter um certo objetivo de vida, que lhes permite ter um rendimento, sendo também importante para "construir" um círculo de amizades ou de colegas que partilhem o mesmo contexto. Portanto, quando este papel social é "roubado", uma parte de cada um é, no fundo, destruída. Lembrando Caleiras (2015), as vidas das pessoas são 'vidas de trabalho' independentemente do facto de estarem descontentes com as condições de trabalho e/ou remuneração. É como se a autossatisfação que sentem por ter um trabalho compensasse todas as outras condições mais negativas que os deixavam descontentes. Este romper com a norma faz com que se sintam descontentes com esta nova posição, situação que se agrava quando se verifica um prolongamento da mesma. A ausência de trabalho contribui para o sentimento de inutilidade do indivíduo uma vez que não realizando nenhuma tarefa, este sente que não está a contribuir para o desenvolvimento da sociedade. Sem trabalho este vê destruído os seus objetivos de vida bem como a sua oportunidade de evoluir enquanto pessoa e profissional pois está privado de aprendizagem. Neste contexto de privação, o trabalhador sente-se frustrado e incapaz.

O desemprego é sempre negativamente vivido e nunca deixa ninguém indiferente quer pela fragilidade económica que este provoca, quer pela falta de realização profissional e sentimento de utilidade inerente ao mesmo. Junto da população mais jovem, verificam-se queixas que se prendem com exploração, trabalhos mal renumerados, incapacidade de organizar a vida pela falta de trabalho. Sentem que estudaram para nada pois o facto de ter uma licenciatura não Ihes facilita o caminho para encontrar um trabalho digno, na sua área de formação, nem Ihes permite obter um salário mais elevado, comparativamente à mão-de-obra não qualificada. Os mais velhos vivem igualmente de forma agonizante esta situação pois pensam que com a idade que possuem não conseguirão encontrar trabalho pela discriminação da idade que tanto se sente atualmente. Portanto, o desemprego é sempre vivido de forma pejorativa pela maioria das pessoas. Todos os indivíduos experimentam sentimentos de desânimo, angústia, desvalorização, inutilidade e até mesmo de revolta (Caleiras, 2015). O autor sustenta ainda que além destes efeitos de caráter psicológico, os indivíduos vivem ainda uma certa resignação, acomodação e desorganização dos modos se vida. O desemprego cria junto dos indivíduos e do seu seio familiar uma certa instabilidade no seu dia-a-dia, insegurança em relação ao futuro, ausência de objetivos e de expetativas de cariz não só profissional, como também afetivo.

O desemprego encontra-se profundamente ligado a situações de risco social. Além das consequências económicas que muitas vezes conduzem à pobreza, uma parte considerável das 
pessoas desempregadas experimentam níveis elevados de depressão, stresse, angústia, desespero, derrotismo e perda de esperança. De acordo com Cook (1991), o desemprego é uma situação de perda, inquietação, isolamento social e uma perda progressiva de otimismo relativamente a encontrar emprego. O mesmo autor sustenta ainda que o desemprego é uma espécie de montanha russa emocional caracterizada por uma perda, preocupação e reações de esgotamento de procura de emprego associado a um sentimento de inadequação, depressão, baixa autoestima, aumento de stresse, isolamento social e tendência crescente para isolamento, doença psiquiátrica, mudanças de estado de espírito ou disposição irregular e perda crescente de otimismo acerca de encontrar emprego.

Diversos estudos têm sido desenvolvidos para compreender as consequências do desemprego junto dos indivíduos que se deparam com uma situação de ausência de trabalho involuntária. Desta forma, verifica-se que o desemprego está associado ao desenvolvimento de distúrbios psicológicos e baixa autoestima, emergência e agravamento de diversos problemas sociais.

A condição de desemprego influencia a vida do desempregado como um todo mesmo quando o desempregado não está a procurar trabalho (que é também uma tarefa bastante desgastante a nível psicológico). As tentativas frustradas de reingresso no mercado de trabalho levam a uma perda de esperança e a um sentimento de desespero. As preocupações inerentes ao desemprego influenciam as outras atividades do desempregado pois afetam a forma como este se relaciona com as outras pessoas como também prejudicam as horas dedicadas ao descanso.

É importante referir que um indivíduo desempregado não é uma pessoa sem trabalho, mas sim alguém que não possui um emprego remunerado. Incluem-se também os indivíduos que se encontram numa situação de desemprego involuntário ou que realizam trabalhos irregulares. Tudo isto pode conduzir, mais cedo ou mais tarde, a atritos no seio familiar, comprometendo o convívio social.

O desemprego aparece, na maior parte das vezes, intimamente ligado à pobreza e à exclusão social. Esta situação leva à necessidade de estudar esta problemática que já não é assumida exclusivamente como um problema meramente económico, mas também como um problema social grave. O desemprego é uma realidade atual sendo um fenómeno maioritariamente associado à vertente económica e às consequências negativas a ele associadas. Contudo, além de ser um grave problema económico, o desemprego constitui principalmente um problema social. É importante referir que os longos períodos de desemprego encontram-se intimamente ligados ao mal-estar psicológico, à deterioração do bem-estar físico do indivíduo bem como à sua desagregação social. Devido à situação de desemprego, a autoestima do indivíduo diminui, este sente-se insatisfeito com a vida, levando-o a isolar-se da sociedade. Podemos referir que o desemprego é um dos maiores fatores de exclusão social que conhecemos uma vez que a diminuição do poder económico do indivíduo desempregado leva-o a, inevitavelmente, abrandar a sua vida social e a deixar de frequentar os habituais contextos de socialização. 


\section{METODOLOGIA}

No presente estudo, desenvolvemos uma metodologia de natureza qualitativa. A abordagem qualitativa é determinante neste género de estudos, uma vez que permite obter uma noção mais ampla dos diversos pontos em análise relativamente à temática do desemprego. Assim, esta opção, além de permitir obter a informação de forma mais profunda, possibilita uma maior flexibilidade aquando da recolha e tratamento da informação, já que esta pode ser recolhida em mais do que um momento.

A opção por esta metodologia tornou possível desenvolver conceitos e chegar à compreensão deste fenómeno a partir de padrões resultantes da recolha de dados. Com a mesma, tivemos a possibilidade de compreender os sujeitos de investigação a partir de quadros de referência, dos significados que atribuem aos acontecimentos, palavras, objetos constituindo, por isso, um sistema analítico de referência determinante.

O campo de análise incidiu sobre os Licenciados em Serviço Social pela Universidade Católica Portuguesa - Faculdade de Ciências Sociais, Centro Regional de Braga visando conhecer as suas vivências e experiências profissionais após terem concluído a licenciatura.

Para a realização deste estudo recorremos a dois instrumentos de recolha de informação: a análise documental e a entrevista semiestruturada.

A opção por este instrumento de recolha de informação afigurou-se fundamental na medida em que se tornava essencial fazer leituras exploratórias bem como a consulta da legislação que permitiu conhecer e explorar melhor a população-alvo bem como a problemática atual do desemprego no seu seio.

\section{APRESENTAÇÃO DOS RESULTADOS}

No processo de investigação é de grande importância analisar todo o material empírico recolhido, uma vez que este constitui um elemento relevante para a compreensão do objeto em estudo. Nesta investigação procedeu-se à recolha de informação empírica através da técnica da entrevista, que foi aplicada junto de indivíduos que frequentaram a Licenciatura, Pós-graduação e Mestrado em Serviço Social na Faculdade Filosofia e Ciências Sociais.

No total foram realizadas 13 entrevistas a pessoas do sexo feminino, com idades compreendidas entre os 26 e os 50 anos de idade. $O$ facto de a amostra ser constituída apenas por elementos do sexo feminino, deveu-se ao facto de apenas estas pessoas se mostrarem interessadas e disponíveis para realização das mesmas, não estando relacionado com nenhum outro aspeto. Não foi necessária a realização de um maior número de entrevistas, visto que estas se revelaram suficientes para a compreensão da temática em questão, que se prende com a Vivência do desemprego por parte dos Assistentes Sociais.

Tendo em conta a análise das entrevistas realizadas, verificamos que sete dos treze indivíduos entrevistados encontram-se desempregados, tratando-se, em alguns casos, de 
um desemprego de longa duração. Sete, do total da amostra, referiu que o primeiro emprego, após a conclusão do percurso académico, foi na sua área de formação, sendo que os restantes seis conseguiram emprego fora da sua área.

Analisando o tempo de espera para encontrar o primeiro emprego após a conclusão dos estudos, verificamos que este varia entre os 6 meses e os 2 anos. Salienta- se o facto de que alguns dos entrevistados já se encontrarem a trabalhar na área ou numa área externa ao Serviço Social, aquando a frequência do curso, dando assim continuidade ao exercício das suas funções após conclusão do curso. Os indivíduos que se encontravam a trabalhar numa área externa ao Serviço Social continuaram a fazê-lo pela necessidade de obter uma remuneração mensal e também pela falta de oportunidades na área. Situação apresentada por um dos entrevistados, quando questionado acerca do tempo de espera até encontrar um emprego na área, referindo que após a conclusão da licenciatura está à procura de trabalho na área.

Os entrevistados que se encontram a trabalhar na área de formação académica revelam que continuam a procurar trabalho de um modo mais concreto como assistentes sociais, sendo que outros referem que "aceitam o que aparecer". Quando questionados sobre as mais-valias do aprofundamento da sua formação aquando a procura de emprego, a maioria dos entrevistados refere não considerar um fator decisivo. Não obstante salientarem que ter maior formação é sempre algo positivo, estes consideram que é um fator de peso aquando da procura de emprego, acrescentando que mais formação seria também um encargo financeiro que, dada a situação de desemprego, muitos não poderiam suportar. A maioria dos entrevistados mostra-se descontente com a sua situação profissional, pois sustentam que estudaram em vão e que não se sentem profissionalmente realizados. Muitos sentem-se frustrados e descontentes e experimentam um sentimento de descrédito em relação à profissão. Na maioria dos casos, a situação de desemprego ou de precariedade laboral em que se encontram afeta a vida pessoal, não conseguindo ter uma vida estável, adquirir bens essenciais e, por isso, algumas vezes têm de recorrer à ajuda financeira de familiares. Esta situação impossibilita a concretização de projetos de vida. Quando questionados acerca da falta de emprego na área em oposição ao crescente aumento de problemáticas sociais, a maioria dos entrevistados defende que o desemprego na área se deve essencialmente ao facto de estarem outros profissionais externos à área a desempenharem as funções nas diversas instituições e organismos que deveriam ser ocupados por alguém com a formação académica adequada, nomeadamente, os assistentes sociais.

Hoje, as empresas e instituições procuram trabalhadores polivalentes e que tenham a capacidade de se adaptarem e de realizarem tarefas inerentes a outros profissionais e, nesse sentido, há profissionais de outras áreas que exercem funções de assistentes sociais. Além disso, como agravante do desemprego na área, os entrevistados apontam outras dificuldades na criação de emprego nesta área, tais como: a falta de verbas financeiras; o facto de haver concursos públicos congelados; pedirem requisitos que não possuem (anos de experiência que não tiveram oportunidade de ter, experiência numa determinada problemática social ou grupo de risco e até conhecimentos de línguas estrangeiras); pedirem relação jurídica com emprego público; a diminuta importância atribuída aos assistentes sociais; os salários muito reduzidos; a exigência de qualificações e de experiência que os candidatos não possuem (e que na sua maioria não 
conseguem obter pela falta de oportunidades) e ainda o fator da idade além do desejável. Um outro motivo apresentado por um dos entrevistados refere-se à forte lacuna da inexistência de uma Ordem que proteja os profissionais do Serviço Social.

\section{CONSIDERAÇÕES FINAIS}

O desemprego constitui um dos principais problemas da sociedade atual, apresentando hoje uma dimensão preocupante uma vez que este fenómeno deixou de ter uma condição temporária fruto da emergência de ciclos económicos recessivos. Hoje este fenómeno atinge todas as profissões e pessoas com elevados níveis de formação profissional.

Nesse sentido, a profissão do assistente social não constitui uma exceção à realidade profissional atual marcada pelo desemprego e pelo emprego precário. Atualmente, a profissão do assistente social começa a ter como um dos desafios a ser enfrentado o problema do desemprego, sendo fulcral desenvolver estudos que permitam compreender as razões que alimentam este fenómeno de forma a tentar contrariar esta tendência uma vez que esta profissão é absolutamente imprescindível para a sociedade.

O desemprego no Serviço Social é uma realidade vincada numa época em que há cada vez mais problemas sociais com necessidade de intervenção.

A partir deste estudo conseguimos compreender que o desemprego na área social não se deve apenas à falta de verbas decorrente da frágil situação económica em que o nosso país se encontra mergulhado, mas a um todo modelo de desenvolvimento que cria emprego precário e desestrutura valores centrais como o da família o que, naturalmente, gera insegurança e instabilidade nas pessoas. Este modelo social é demasiado flexível, o que leva a que outros profissionais externos à área ocupem os cargos que deveriam ser ocupados pelos assistentes sociais. Portanto, é lícito afirmar que o facto de colocarem outros profissionais externos ao serviço social a realizar as tarefas dos assistentes sociais quando há imensos profissionais na área no desemprego, aponta para uma desvalorização da profissão e a um não reconhecimento da mesma.

A situação de desemprego ou de precariedade laboral em que muitos se encontram impede a sua realização profissional e pessoal pois muitos não conseguem concretizar os seus objetivos de vida. Esta situação desperta um sentimento de revolta, de frustração e de desacreditar na profissão.

É verdade que hoje já demos um passo em relação ao passado quando muitos problemas sociais eram desconhecidos ou desvalorizados. Apesar da evolução ainda nos encontramos muito longe do lugar em que estas questões deveriam de ser colocadas dada a sua importância pois daí depende uma vida digna e sadia para muitas pessoas.

Ainda há um longo caminho a percorrer neste sentido e é necessário caminhar a passos largos, pois, os problemas sociais da atualidade são graves e muitas pessoas vivem em condições deploráveis e com necessidade de intervenção. 


\section{REFERÊNCIAS}

Alves, G. (2000). Trabalho e Mundialização do Capital. Londrina: Praxis.

Antunes, R. (2000). Os Sentidos do Trabalho: Ensaio sobre a Afirmação e Negação do Trabalho. São Paulo: Boitempo.

Bauman, Z. (1925). O Mal-estar da Pós-Modernidade. Rio de Janeiro: Jorge Zahar.

Barreto, A. (2002). Mudança Social em Portugal 1960/2000. Instituto de Ciências Sociais: Universidade de Lisboa.

Caleiras, J. (2015). Para lá dos Números: As consequências pessoais do desemprego. Lisboa: Almedina.

Campos, A. \& Conceição, H. (2007). Mercado de Trabalho Emprego e Desemprego. Instituto Politécnico de Coimbra, Departamento de Engenharia.

Carvalho, M. I. (2010). Serviço social em Portugal: percurso cruzado entre a assistência e os direitos. Revista de Serviço Social e Saúde UNICAMP - Campinas, vol. IX, no 10, 147-164.

Carvalho, M. I. (2011). Serviço social e sistema de bem-estar: semelhanças e diferenças entre Portugal, Espanha e Alemanha. Serviço Social Revista, Londrina, vol.13, no 2, 4-18.

Castel, R. (1997). As Metamorfoses da Questão Social: uma crónica do salário. Tradução de Iraci D. Poleti. Petrópolis, Rio de Janeiro: Vozes.

Castells, M. (2005). Globalización e identidad in Dossier- Quaderns de la Mediterrania, 5 Los valores hoy. 5. [Instituto Europeo del Mediterráneo]. Retrieved from http://www.iemed.org/publicacions/quaderns/5/ecastells.

Cook, E. P. (1991). Annual Review: Practice and Research in career counseling and development. The career development quarterly, 40 (2), 99-132.

Chaves, C. N. (2010). Serviço social e políticas sociais: a relação teoria e prática em questão. Tese de mestrado, Universidade Federal Rio de Janeiro, Centro de Filosofia e Ciências Humanas, Escola de Serviço Social, Rio de Janeiro, Brasil.

Chiavenato, I. (2000). Introdução à Teoria Geral da Administração. 6ạ. Edição. São Paulo: Editora Campus.

Darwin, Ch. (2010). A Origem das Espécies. São Paulo: Coleção: Livros que mudaram o mundo.

De Masi, D. (2000). A Sociedade Pós-Industrial. 3ạ. Edição. São Paulo: Editora Senac.

Duque, E. (2003). A Identidade na pós-modernidade: um conceito histórico-hipotético. Cadernos do Noroeste, 21, 1-2, 39-51.

Duque, E., Calheiros, A. (2011). Trabalho, igualdade e inclusividade na pós-modernidade. Pessoas \& Sintomas, $15,46-51$.

Duque, E. (2012). Contributos para uma crítica da aceleração do tempo", In Araújo, E.; Duque, E. 
(2012). Os tempos sociais e o mundo contemporâneo. Um debate para as Ciências Sociais e Humanas. Braga: Centro de Estudos de Comunicação e Sociedade/Centro de Investigação em Ciências Sociais.

Duque, E. (2013), Work Values in Portuguese Society and in Europe. In A. P. Marques, C. Gonçalves, L. Veloso (coord.), Trabalho, organizações e profissões: recomposições conceptuais e desafios empíricos (pp. 81-98). Secção temática Trabalho, Organizações e Profissões, Associação Portuguesa de Sociologia.

Drucker, P. (1999). Sociedade Pós-Capitalista. São Paulo: Editora Pioneira.

Eufrásio, M. A. P. (2011). As Transformações no Mundo do Trabalho Frente à Globalização. Revista Labor, 1, 5, 190-209.

Esping-Andersen, G. (1990). The Three Worlds of Welfare Capitalism. Princeton: Princeton University Press.

Freire, J. (2000). Atitudes Face ao Emprego, Trabalho e Tempo Livre. Lisboa: Observatório do Emprego e Formação Profissional.

Freire, J. (2009). Trabalho, emprego e cidadania. Sociologia, vol. 19, Porto: Departamento de Sociologia da Faculdade de Letras da Universidade do Porto.

Gameiro, A. M. (2007). Relevância da segurança jurídica no modelo de Estado Transnacional. Revista de Direito Público. V. 2, n. 1, Ed. UEL. Londrina-PR.

Giddens, A. (2010). O Trabalho e a Vida Económica. Lisboa: Fundação Calouste Gulbenkian.

Gonçalves, C. (2009). Desenvolvimento do estudo: notas teórico-metodológicas. In C. Gonçalves (org.), Licenciados, precariedade e família (pp. 19-60). Porto: Estratégias Criativas.

Guerra, I. C. (2006), Pesquisa Qualitativa e Análise de Conteúdo. Estoril: Principia.

Habermas, J. (2001). A Constelação Pós-Nacional: ensaios políticos. São Paulo: Littera Mundi.

Hespanha, P. (2002). Mal-estar e Risco Social num Mundo Globalizado: Novos problemas e novos desafios para a teoria social. In B. Sousa Santos (Org.), Globalização: Fatalidade ou Utopia. Porto: Afrontamento.

Kovács, I. (2006). Novas formas de organização do trabalho e autonomia no trabalho. Retrieved from http://www.scielo.oces.mctes.pt/pdf/spp/n52/n52a03.pdf

Mariotto, F. L. (1991). O Conceito de Competitividade da empresa: uma análise crítica. São Paulo: RAE.

Martins, A. \& Tomé, M. R. (2008). Estado Atual da Formação em Serviço Social em Portugal problemas e desafios à organização profissional. 19a Conferência Mundial de Serviço Social, IFSW e CFESS, Brasil, Salvador - Bahia.

Marques, A. P. (2006). Entre o Diploma e o Emprego: A Inserção Profissional dos Jovens Engenheiros. Porto: Afrontamento.

Marques, A. P. (2009), Trajetórias Quebradas: A Vivência do Desemprego de Longa duração. Porto: 
Profedições.

Marx, K. (1985). O Capital: crítica da economia política. São Paulo: Abril Cultural.

Mouro, H. \& Simões, D. (2001). Cem anos de Serviço Social. Coimbra: Quarteto Editora.

Nogami, O. \& Passos, C. (1988). Princípios de Economia. São Paulo: Pioneira.

Nunes, M. H. (2010). Serviço Social em Contexto: Política Social e Serviço Social. Trabajo Social Global. Revista de Investigaciones en Intervención Social, 1 (1), 59-79.

Outhwaite, W. \& Bottomore, T. (Org.) (1996). Dicionário do Pensamento Social do Século XX. Rio de Janeiro: Jorge Zahar.

Rebelo, G. (2000). Emprego e formas de precariedade da actividade laboral: o caso de Portugal no contexto da EU, Lisboa, Universidade Técnica de Lisboa. Dissertação de Doutoramento. Instituto Superior de Economia e Gestão.

Rodrigues, F. (1999). Assistência social e políticas sociais em Portugal. Lisboa: ISSS - Departamento editorial; CPIHTS- Centro Português de História e de Investigação em Trabalho Social.

Santos, B. S. (2000). Os Processos da globalização. In B. Sousa Santos (org.), Globalização: fatalidade ou utopia? (pp. 37-42). Porto: Edições Afrontamento.

Santos, V. C. (2009). Da Era Fordista ao Desemprego Estrutural da Força de Trabalho: Mudanças na Organização da Produção e do Trabalho e seus Reflexos. VI Colóquio Internacional Marx e Engels. $\quad$ Retrieved from https://www.ifch.unicamp.br/formulario_cemarx/selecao/2009/trabalhos/da-era-fordista-aodesemprego-estrutural-.pdf

Sennett, R. (1999). A Corrosão do Caráter - As Consequências Pessoais do Trabalho no Novo Capitalismo. Lisboa: Terramar.

Tumolo, L. M. S. \& Tumolo, P. S. (2004). A Vivência do Desemprego: Um Estudo Crítico do Significado do Desemprego no Capitalismo. Trabalho, Educação e Saúde, 2, 2, 327-344. 